University of Nebraska - Lincoln

DigitalCommons@University of Nebraska - Lincoln

Publications, Agencies and Staff of the U.S.

Department of Commerce

U.S. Department of Commerce

2011

\title{
Humpback whale abundance in the North Pacific estimated by photographic capture-recapture with bias correction from simulation studies
}

\author{
Jay Barlow \\ NOAA, jay.barlow@noaa.gov \\ John Calambokidis \\ Cascadia Research Collective \\ Erin A. Falcone \\ Cascadia Research Collective \\ C. Scott Baker \\ Oregon State University, scott.baker@oregonstate.edu \\ Alexander M. Burdin \\ Russian Academy of Sciences

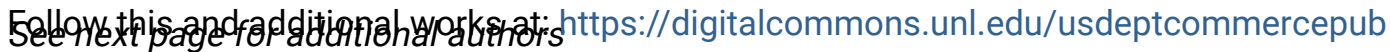 \\ Part of the Environmental Sciences Commons
}

Barlow, Jay; Calambokidis, John; Falcone, Erin A.; Baker, C. Scott; Burdin, Alexander M.; Clapham, Phillip J.; Ford, John K. B.; Gabriele, Christine M.; LeDuc, Richard; Mattila, David K.; Quinn, Terrance J. Il; RojasBracho, Lorenzo; Straley, Janice M.; Taylor, Barbara L.; R., Jorge Urbán; Wade, Paul; Weller, David; Witteveen, Briana H.; and Yamaguchi, Manami, "Humpback whale abundance in the North Pacific estimated by photographic capture-recapture with bias correction from simulation studies" (2011). Publications, Agencies and Staff of the U.S. Department of Commerce. 239.

https://digitalcommons.unl.edu/usdeptcommercepub/239

This Article is brought to you for free and open access by the U.S. Department of Commerce at DigitalCommons@University of Nebraska - Lincoln. It has been accepted for inclusion in Publications, Agencies and Staff of the U.S. Department of Commerce by an authorized administrator of DigitalCommons@University of Nebraska - Lincoln. 


\section{Authors}

Jay Barlow, John Calambokidis, Erin A. Falcone, C. Scott Baker, Alexander M. Burdin, Phillip J. Clapham, John K. B. Ford, Christine M. Gabriele, Richard LeDuc, David K. Mattila, Terrance J. Quinn II, Lorenzo RojasBracho, Janice M. Straley, Barbara L. Taylor, Jorge Urbán R., Paul Wade, David Weller, Briana H. Witteveen, and Manami Yamaguchi 
MARINE MAMMAL SCIENCE, 27(4): 793-818 (October 2011)

2011 by the Society for Marine Mammalogy

Published 2011. This article is a US Government work and is in the public domain in the USA.

DOI: $10.1111 / \mathrm{j} .1748-7692.2010 .00444 . x$

\title{
Humpback whale abundance in the North Pacific estimated by photographic capture-recapture with bias correction from simulation studies
}

\author{
JAY BARLOW \\ NOAA, National Marine Fisheries Service, \\ Southwest Fisheries Science Center, \\ 3333 N. Torrey Pines Court, \\ La Jolla, California 92037, U.S.A. \\ E-mail: jay.barlow@noaa.gov \\ John CALAMBokidis \\ ERIN A. FALCONE ${ }^{1}$ \\ Cascadia Research Collective, \\ 218 1/2 W. 4th Avenue, \\ Olympia, Washington 98501, U.S.A. \\ C. SCOTT BAKER
}

Marine Mammal Institute and Department of Fisheries and Wildlife,

Oregon State University,

Newport, Oregon 97365, U.S.A.

Alexander M. Burdin

Kamchatka Branch, Pacific Institute of Geography,

Russian Academy of Sciences,

Partizanskaya, 6, Petropavlovsk-Kamchatsky, 683000, Russia

Phillip J. Clapham

NOAA, National Marine Fisheries Service,

Alaska Fisheries Science Center,

7600 Sand Point Way N.E.,

Seattle, Washington 98115 , U.S.A.

JOHN K. B. FORD

Fisheries and Oceans Canada,

Pacific Biological Station,

3190 Hammond Bay Road,

Nanaimo, British Columbia V9T 6N7, Canada

Christine M. Gabriele

Glacier Bay National Park,

1 Park Road,

Gustavus, Alaska 99826, U.S.A.

\footnotetext{
${ }^{1}$ Subsequent authors are listed alphabetically.
} 


\section{RICHARD LEDUC}

NOAA, National Marine Fisheries Service, Southwest Fisheries Science Center, 3333 N. Torrey Pines Court,

La Jolla, California 92037, U.S.A.

\section{David K. MatTila}

Hawaiian Islands Humpback Whale National Marine Sanctuary, 726 South Kihei Road,

Kihei, Hawaii 96753, U.S.A.

Terrance J. QuinN II

Juneau Center, School of Fisheries and Ocean Sciences,

University of Alaska Fairbanks, 17101 Pt. Lena Loop Road, Juneau, Alaska 99801 U.S.A.

\section{LORENZO ROJAS-BRACHO}

Instituto Nacional de Ecología, $c / \%$ CICESE,

Km. 107 Carretera Ensenada-Tijuana, Ensenada, Baja California 22860, Mexico

JANice M. STRALEY

University of Alaska Southeast, 1332 Seward Avenue, Sitka, Alaska 99835, U.S.A.

\section{BARBARA L. TAYLOR}

NOAA, National Marine Fisheries Service, Southwest Fisheries Science Center, 3333 N. Torrey Pines Court,

La Jolla, California 92037, U.S.A.

\section{Jorge Urbán R.}

Universidad Autonoma de Baja California Sur, Ap. Post 19-B,

La Paz, Baja California Sur 23081, Mexico

\section{Paul Wade}

NOAA, National Marine Fisheries Service, Alaska Fisheries Science Center, 7600 Sand Point Way N.E., Seattle, Washington 98115, U.S.A.

\section{DAVID WeLLER}

NOAA, National Marine Fisheries Service, Southwest Fisheries Science Center, 3333 N. Torrey Pines Court, La Jolla, California 92037, U.S.A. 


\author{
BRIANA H. WITTEVEEN \\ University of Alaska Fairbanks, \\ 117 Trident Way, \\ Kodiak, Alaska 99615, U.S.A. \\ MANAMI YAMAGUCHI ${ }^{2}$ \\ Ogasawara Marine Center, \\ Byobudani, Chichijima, Ogasawara-mura, \\ Tokyo 100-21, Japan
}

\begin{abstract}
We estimated the abundance of humpback whales in the North Pacific by capturerecapture methods using over 18,000 fluke identification photographs collected in 2004-2006. Our best estimate of abundance was $21,808(C V=0.04)$. We estimated the biases in this value using a simulation model. Births and deaths, which violate the assumption of a closed population, resulted in a bias of $+5.2 \%$, exclusion of calves in samples resulted in a bias of $-10.5 \%$, failure to achieve random geographic sampling resulted in a bias of $-0.4 \%$, and missed matches resulted in a bias of $+9.3 \%$. Known sex-biased sampling favoring males in breeding areas did not add significant bias if both sexes are proportionately sampled in the feeding areas. Our best estimate of abundance was 21,063 after accounting for a net bias of $+3.5 \%$. This estimate is likely to be lower than the true abundance due to two additional sources of bias: individual heterogeneity in the probability of being sampled (unquantified) and the likely existence of an unknown and unsampled breeding area $(-8.7 \%)$. Results confirm that the overall humpback whale population in the North Pacific has continued to increase and is now greater than some prior estimates of prewhaling abundance.
\end{abstract}

Key words: humpback whale, Megaptera novaeangliae, North Pacific, abundance, photo-identification, capture-recapture, bias, simulation model.

Humpback whales (Megaptera novaeangliae) are found in all major ocean basins and typically undergo seasonal migrations from feeding areas in high latitudes to breeding areas in low latitudes (Mackintosh 1946). In the North Pacific, humpback whales feed primarily along the Pacific Rim from California, U.S.A. to Kamchatka, Russia and migrate to breeding areas along the coasts of Central America and Mexico and around the offshore islands of Mexico, Hawaii, and the western Pacific (Calambokidis et al. 2001). Commercial whaling in the North Pacific was banned in 1966 by which time the North Pacific population had been reduced from an estimated 15,000 prior to 1905 (Rice 1978) to approximately 1,200-1,400 (Gambell 1976, Johnson and Wolman 1984). Although there is considerable uncertainty in these early estimates of abundance, humpback whale populations in the North Pacific were clearly reduced to low numbers by whaling, as they were elsewhere around the world (Johnson and Wolman 1984).

Methods to estimate the abundance of whale populations have improved tremendously since the end of whaling. The identification of individuals based on the

\footnotetext{
${ }^{2}$ Current address: Mt. Coffee, Komagari, Chichi-jima, Ogasawara, Tokyo 100-2101.
} 
natural markings on the ventral surface of their flukes has been combined with mark-recapture methods (here more appropriately called capture-recapture methods) to estimate population sizes (Katona et al. 1979, Hammond 1986). The same capture-recapture concept has also been paired with genetic identification of individuals to estimate humpback abundance in the North Atlantic (Palsbøll et al. 1997, Smith et al. 1999). Line-transect survey methods (Burnham and Anderson 1976, Buckland et al. 2001) have also advanced during this time period and have been used to estimate humpback whale abundance in the North Pacific (Barlow and Forney 2007, Zerbini et al. 2006). A direct comparison of photographic capture-recapture and line-transect methods in the same area showed that both methods gave similar results (Calambokidis and Barlow 2004), but the interpretation of such results can differ depending on the method used. Capture-recapture methods typically estimate the entire population inhabiting a region whose boundaries may be difficult to define. Line-transect methods, in contrast, estimate the average number of whales present within a defined study area during the period of a survey.

In the North Atlantic, a large-scale photo-identification sampling program in 1992-1993 was conducted to estimate humpback whale abundance as part of the Year of the North Atlantic Humpback (YONAH) project. Summer sampling took place in multiple feeding areas from the Gulf of Maine to Norway. Winter samples were collected in four locations within the West Indies. The entire population of humpback whales in the North Atlantic was estimated to be approximately 11,570 (95\% CI $=10,290-13,390)$ based on capture-recapture methods using a modified Petersen estimator (Stevick et al. 2003). That estimate was based on pooling feeding area and breeding area samples over $2 \mathrm{yr}$ to improve precision. Prior to this study, there had never been a dedicated sampling effort to similarly estimate humpback whale abundance in the entire North Pacific.

In the past $25 \mathrm{yr}$, humpback whale abundance has been estimated for various breeding areas within the North Pacific using both photographic capture-recapture and line-transect methods. Capture-recapture estimates for the Hawaii breeding area increase from 895 (95\% CI = 592-1,837) in 1977-1979 (Darling et al. 1983) to $1,407$ (95\% CI $=1,113-1,701)$ in 1980-1983 (Baker and Herman 1987), and this population was estimated to have increased to 3,000-5,000 by the early $1990 \mathrm{~s}$ (Cerchio 1998). Aerial line-transect methods were used to estimate that humpback populations near the main Hawaiian Islands had increased from 2,754 (95\% CI = $2,044-3,463)$ in 1993 to 4,491 $(95 \% \mathrm{CI}=3,146-5,836)$ in 2000 (Mobley et al. 2001). Urbán et al. (1999) used capture-recapture methods to estimate a Mexico breeding population of approximately $2,700(\mathrm{CV} \approx 0.16$, calculated from CIs) humpback whales in 1991-1992.

Both photographic and transect methods have also been used to estimate abundance in some North Pacific summer feeding areas. Calambokidis and Barlow (2004) estimated that the feeding population along the U.S. West Coast had increased from approximately $570(\mathrm{CV}=0.05)$ in $1991-1992$ to approximately $840(\mathrm{CV}=0.16)$ in 1996-1997 based on capture-recapture methods and found that these numbers were generally in agreement with line-transect estimates. Barlow and Forney (2007) estimated the 2005 abundance of the U.S. West Coast population to be 1,145 (no CV estimate) humpback whales using line-transect methods. Based on photographic capture-recapture methods, the abundance of humpback whales in southeast Alaska was estimated as 374 (95\% CI $=327-421)$ in 1979-1983 (Baker et al. 1986), $547(95 \% \mathrm{CI}=504-590)$ in 1986 (Baker et al. 1992), and 961 (95\% CI $=657-$ 1,076) in 2000 (Straley et al. 2009). Zerbini et al. (2006) estimated a population 
size of 2,644 (95\% CI = 1,899-3,680) humpback whales based on ship line-transect surveys in western Alaska (near the Alaska Peninsula and eastern Aleutian Islands) and calculated a population growth rate of $6.6 \% \mathrm{yr}^{-1}\left(95 \% \mathrm{CI}=5.2 \%-8.6 \% \mathrm{yr}^{-1}\right)$.

In general, humpback whale abundance in the North Pacific appears to now be much greater than when whaling ended, and the numbers appear to be increasing in all of the areas where multiple estimates have been obtained over a period of multiple years. However, these regional studies do not provide the whole picture. We know from genetic studies (Baker et al. 1986, Baker et al. 1998, Witteveen et al. 2004) and from photographic matches among different areas (reviewed by Calambokidis et al. 2001), that populations in the North Pacific are geographically structured and that the humpback migration patterns are complex. Thus, there is no simple way to add all the regional estimates together to obtain an overall estimate of abundance in the ocean basin. The abundance of humpback whales in the entire North Pacific has been estimated only once in recent years. Calambokidis et al. (1997) conducted a retrospective study of humpback identification photographs that had been taken for regional studies from 1990 to 1993 to estimate the abundance of whales in the North Pacific. They used a Darroch's geographically stratified capture-recapture model and estimated a total population size of $6,010(\mathrm{CV}=0.08)$ or approximately 8,000 whales after corrected for a sex bias in the breeding areas. No basin-wide humpback population estimates have been made since then; however, given evidence of growth in all well-studied regions, we expect that the abundance in the North Pacific has increased since the early 1990s.

Here, we estimate the abundance of humpback whales in the North Pacific from 2004 to 2006 based on a dedicated photo-identification sampling program called SPLASH (Structure of Populations, Levels of Abundance and Status of Humpbacks). The SPLASH study was designed to representatively sample all known feeding and breeding populations in the North Pacific. We use the Chapman-Petersen closed population model to estimate whale abundance. As has been done previously to estimate humpback whale abundance in the North Atlantic (Stevick et al. 2003), we include whales photographically sampled in breeding areas as one sample (capture event) and whales sampled in summer feeding areas as a second sample (recapture), thus using the migration to help randomize sampling. This approach also avoids many of the sources of heterogeneity that would result from sampling (capture and recapture) in only one seasonal habitat (Smith et al. 1999). We use a population growth model, a migration model, and a sampling simulation to examine the effects of factors that might bias our estimates: (1) biased sex ratios in the breeding areas, (2) births and deaths during the sampling period, (3) heterogeneity in capture probabilities, (4) geographic structure in the population and in the sampling, and (5) the presence of an unknown, unsampled breeding area. We use these simulations to develop bias corrections to improve our estimates of abundance. We make the simulation results available electronically for use by other researchers in testing alternative capture-recapture models. Finally, we use these new estimates to help evaluate the current status of humpback whales in the North Pacific.

\section{METHODS}

\section{Field Methods}

Photographs were taken of the ventral side of humpback whale flukes using digital SLR cameras. Most photographs were taken from small, 6-8 $\mathrm{m}$ boats making day 


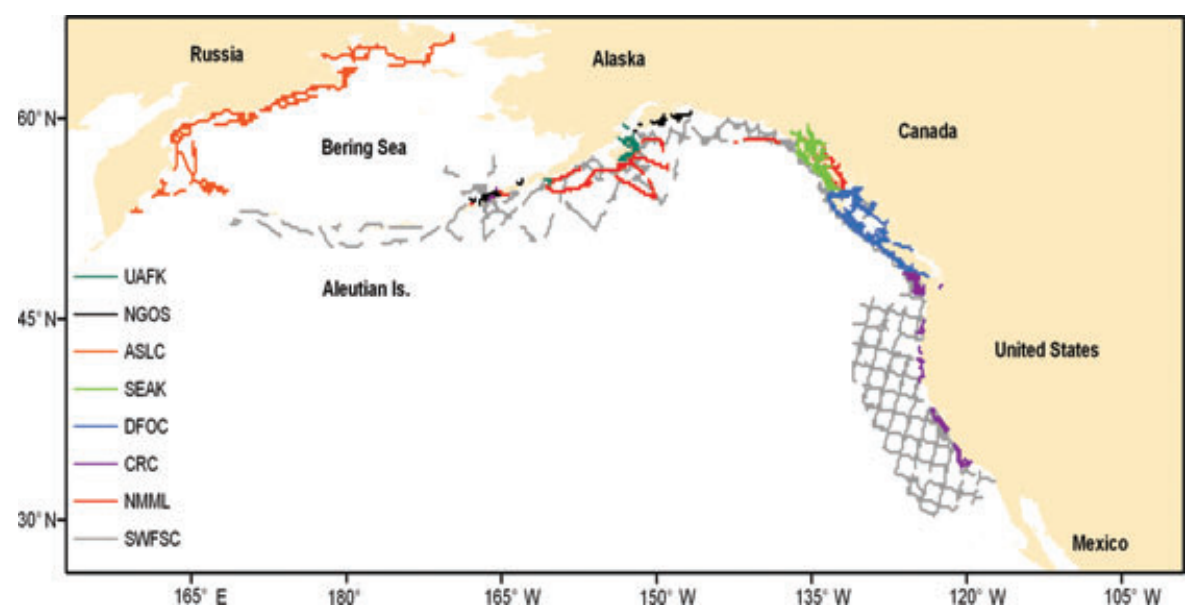

Figure 1. Transect lines of vessels conducting dedicated photo-identification efforts for the SPLASH project in feeding areas. Colors indicate the research groups conducting those studies (UAFK-University of Alaska, Kodiak; NGOS-North Gulf Oceanic Society; ASLC Alaska Sea Life Center; SEAK—Southeast Alaska research consortium; DFOC_Department of Fisheries and Oceans Canada; CRC_-Cascadia Research Collective; NMML_National Marine Mammal Lab; SWFSC_-Southwest Fisheries Science Center). Breeding area sampling was largely very close to shore and cannot be shown at this scale.

trips from shore. Small boat sampling locations included the western Pacific (Ogasawara Islands, the Ryukyu Islands [Okinawa], and the Philippines), the Hawaiian Islands (Kauai, Oahu, Maui, and Hawaii), Mexican offshore islands (the Revillagigedo Archipelago), Baja California, Mexico (mostly between La Paz and Cabo San Lucas), mainland Mexico (Bahia de Banderas, Isla Isabel, and the Islas Tres Marias), Central America (Guatemala, El Salvador, Nicaragua, and Costa Rica), the U.S. West Coast (from many different ports), British Columbia (mostly west of Vancouver Island and the mainland coast), and Alaska (southeastern Alaska, Prince William Sound, Kenai Peninsula, Kodiak Island, Barren Islands, Shumagin Islands, and Unalaska Island). A variety of larger vessels were used to sample more remote and offshore locations, often together with small boats launched from those ships. Search effort for larger vessels is shown in Figure 1.

Sampling effort was allocated based on a priori appraisal of the relative number of humpback whales in each sampling area, as well as the availability of researchers and resources. In areas that lacked any quantitative data, effort was allocated based on expert opinion within the SPLASH steering committee. The North Pacific was divided into sampling regions, and a regional coordinator was assigned to ensure representative sampling from each region. Coordinators were designated for 11 regions including Asia (Japan and the Philippines), Hawaii, Mexico, Central America, the U.S. West Coast, British Columbia, southeast Alaska, the northern Gulf of Alaska and Bering Sea near shore areas, Kodiak and Shumagin Islands, Alaska offshore areas, and Russia. Coordination in some of these 11 regions was shared among two or more individuals.

Sampling protocols were provided in writing to all participants (see supplemental online material). The fluke photographic protocols were designed to avoid 
heterogeneity in the likelihood of sampling different individuals or demographic classes and thereby to avoid biases in mark-recapture abundance estimates. To avoid under-sampling those individuals that raise their flukes out of the water ("fluke up") less often, participants were directed to stay with the group until identification photographs had been obtained from all animals in the group, or until a minimum of three dive series or $30 \mathrm{~min}$ had passed, whichever occurred first. Groups could be left early when required for logistical/safety reasons or when shifting to other groups was required to obtain a better sample of identifications in a region when time was limited. For multiple groups of whales encountered in close proximity, participants were instructed to photograph whales while moving consistently through the area, in order to obtain as large and representative a sample of all animals as possible. To avoid preferentially sampling one sex (especially during winter sampling) or age class, participants were instructed not to collect SPLASH samples during directed studies of females and calves, competitive male groups, or any other particular sex or age class and to randomly sample all encountered whales. Sampling protocols also specified a set of data to be collected by all SPLASH participants, including information on search effort and each humpback whale that was encountered.

In addition to taking fluke photographs for individual identification, protocols specified several other types of sampling. Biopsy samples were taken for population genetic analysis and sex identification, as well as isotope studies, pollutant, and other biochemical studies. Photographs were also taken of dorsal fins, lateral flanks, and tailstocks to study scarring patterns that might be associated with ship strikes or entanglement in fishing gear and other lines and to study whale health using indices of skin and body condition. Results from these other studies will be presented elsewhere.

\section{Photographic Quality Control and Matching}

Individual data contributors submitted all photographs to their regional coordinator. Regional coordinators identified the best fluke photograph from each encounter (if individual contributors had not) and compared the best photograph from each encounter with all others, even if the best photograph was of low quality. Each season, the regional coordinators submitted all photographs, a database identifying within-season matches, and the identified best photograph of each whale to the overall SPLASH coordinator for between region and between season matching. The SPLASH data coordinator rated each fluke photograph for pigmentation pattern (five ranked categories from all white to all black), photographic quality (ranked 1-5 on each of five features: proportion visible, vertical angle, lateral angle, focus/sharpness, and exposure; see supplemental online material for details on the categories and rank scores), and other characteristics (ranked 1-5 on each of three features: distinctiveness of trailing edge, degree of scarring, and presence of killer whale [Orcinus orca] tooth rake marks). To ensure consistency, photographs were rated by the same person throughout this study.

Photographic matching was conducted by a team of six people experienced in matching humpback whale photographs. Matches were identified by eye from $6 \times$ $9 \mathrm{~cm}$ prints that were tightly cropped around the image of the fluke and mounted, nine-to-a-page, in clear plastic sleeves. Suspected matches were verified by a second matcher. Several shortcuts were implemented to improve the efficiency of matching efforts and to effectively deal with the vast number of photographs collected during 
the five SPLASH sampling seasons. Friday et al. (2008) showed that the best tradeoff between bias and precision for humpback capture-recapture estimates in the Atlantic was obtained by eliminating photographs of partial or half flukes and photographs in the poorest of four categories of photographic quality. We did not attempt to match photographs with a score of 4 or 5 in any of the five measures of photographic quality (e.g., eliminating flukes with less than $50 \%$ visible) and photographs with a score of three in four or more measures of quality. The ranked measures of fluke distinctiveness were not used in our analyses.

Each season, a catalog was constructed for each region using the single best photograph of each individual seen in that region and season. For example, four catalogs were assembled for winter 2004 corresponding to Asia, Hawaii, Mexico, and Central America. Within each catalog, images were ordered in 15 categories of pigmentation ranging from all white to all black. When matching photographs to an existing catalog, photographs within the same pigmentation category were searched first, and, if a match was not found, photographs within two adjacent pigmentation categories were searched. These regional-seasonal catalogs were maintained throughout the matching process to facilitate workflow by multiple matchers. Catalog images from a new season were first matched to the same region in previous seasons (i.e., a new photograph from Hawaii 2005 was first matched to the Hawaii 2004 catalog). If a match was not found, the image was then matched to the most likely opposite-season region (i.e., a new photograph from Hawaii 2005 would be matched next to southeast Alaska 2004, then the Gulf of Alaska 2004, then British Columbia 2004 , etc.). Finally, new images would be matched to all other regions in the same season. If a match was found with an existing catalog, the remaining catalogs were not searched since they had already been internally reconciled. The best available photograph of each identified whale was used in the catalog regardless of when or where that image was taken. If a whale was photographed more than once in a given season, the sampling location of that whale was assigned to be the location where the whale was photographed closest in time to the midpoint of the season (taken to be 1 March for breeding areas and 1 August for feeding areas).

Two approaches were used to quantify the number of between-season matches that were missed by our matching process. First, different teams of matchers repeated pair-wise comparisons between nine pairs of catalogs, each representing one season's sampling in one area. There were a total of 165 known matches in 3,779 possible comparisons, and the second team found 148 of these. In addition, to help estimate match success rate, photographs of 266 individuals that were known to match previous catalogs were added to the 2006 season matching effort. These "seeded" photographs were not the identical images in those catalogs, and the matchers did not know which photographs had been added.

\section{Abundance Estimation}

The primary assumption of capture-recapture methods is that at least one of the sample occasions (capture or recapture) is random with respect to all individuals in the population. Departures from purely random sampling result in sampling heterogeneity. In most capture-recapture studies, heterogeneity results in a higher probability of resampling the same individuals and results in an underestimate of population size (Hammond 1990). In whale capture-recapture studies, sample heterogeneity can arise from many sources: (1) individual behavioral difference (e.g., 
approachability or tendency to fluke up prior to a dive), (2) geographic preferences of whales combined with non-random geographic coverage, and (3) biased sex ratios in breeding areas. Mortality, reproduction, emigration, and immigration during the sampling period can be viewed as heterogeneity affecting the likelihood of an individual being sampled in different sampling periods.

A large number of statistical models are available to estimate population size (as well as survival rates, recruitment, and population growth rates) from capturerecapture data. Increasingly sophisticated capture-recapture models have evolved to correct the bias caused when real-world data fail to meet the assumptions of the previous generation of models. The first and simplest model is Petersen's two-sample closed model to estimate abundance (Petersen 1896). The Cormack-Jolly-Seber (CJS) model corrects the bias caused by mortality during the sampling period and estimates a survival parameter. Robust design models (Kendall et al. 1995) improves CJS models by using short (closed) capture sessions to better estimate capture probability separate from survival probability. Jolly-Seber models further relax the assumption of closed populations by also estimating recruitment into a population. Darroch's method explicitly models heterogeneity in capture probability caused by geographic stratification and extensions allow for survival rate estimation. Hilborn (1990) further extended this approach to multiple sampling periods. Hwang and Chao (1995) deal more generally with heterogeneity of capture probability in capture-recapture models. However, none of these available models deal simultaneously with all of the violations in capture-recapture assumptions that are found in our data.

Simulation is an alternative approach to correcting the biases that result from violations in capture-recapture model assumptions. This approach can be used when analytical approaches fail. Carothers (1979) and Pledger and Efford (1998) used simulation models and inverse prediction to estimate the bias associated with sampling heterogeneity. Because our time period is so short (a maximum of $1.5 \mathrm{yr}$ between feeding area and breeding area samples), it is not practical to estimate parameters of an open population model (survival rate, recruitment rate, emigration rate, etc.). Estimates of survival rates and recruitment rates for humpback whales in the North Pacific have already been estimated from much longer time series (Gabriele et al. 2001, Mizroch et al. 2004). After considering alternative models, we selected the simple two-sample Petersen estimator and used simulation modeling to develop correction factors for violations in capture-recapture assumptions. These simulations use available information on survival and recruitment rates to correct for biases in this closed population model. Similarly, Stevic (2003) examined available capturerecapture models and selected the Petersen model to estimate the abundance of humpback whales in the North Atlantic based on very similar data.

Here we use the Chapman modification of the Petersen capture-recapture model (Chapman 1951) to estimate population size, $N$

$$
N=\left[\left(n_{1}+1\right)\left(n_{2}+1\right) /(m+1)\right]-1,
$$

where $n_{1}$ is the number of unique individuals photographed during the first capture period, $n_{2}$ is the number photographed during the second capture period, and $m$ is the number of photographic matches between the first and second periods. The approximate analytical variance of this estimate is

$$
\operatorname{Var}(N)=\left[\left(n_{1}+1\right)\left(n_{2}+1\right)\left(n_{1}-m\right)\left(n_{2}-m\right)\right] /\left[(m+1)^{2}(m+2)\right]
$$


Seber (1982). In addition to the above assumptions of random sampling, this model also assumes that populations are closed and there is no immigration, emigration, births, or deaths during the sampling period.

We designed our analysis to minimize the effects of sampling heterogeneity and demographic processes (births and deaths) on the results. Individual behavior is very different in feeding and breeding areas so, to minimize behavioral heterogeneity, we estimated abundance using one area as the initial capture occasion and the other area as the recapture. This approach also reduced the effect of geographic heterogeneity because there was no overlap in sampling locations between capture occasions. To minimize the effect of births and deaths in a closed population model, we compared consecutive sampling occasions that were separated by as short a time period as possible (approximately $6 \mathrm{mo}$ ). To eliminate the effect of immigration and emigration, we estimated the size for the entire North Pacific, which is considered to be a closed population. Population size was also estimated based on the multiyear comparison of all feeding area samples (2004-2005 pooled) to all breeding area samples (2004-2006 pooled).

\section{Simulation Studies and Bias Correction}

Although we designed sampling and analysis methods to minimize bias, there is no way to eliminate all potential sources of bias. We developed a simulation program called SimSPLASH ${ }^{3}$ to determine the likely magnitude of biases that could not be eliminated, and we applied bias-corrections where appropriate. SimSPLASH is a stochastic, geographically structured, individual-based model that simulates the photographic sampling of humpback whales in feeding and breeding areas. In the model, individual whales have six traits: sex, age class (calf $<1$-yr-old/noncalf), status (dead/alive), home feeding area, and probabilities of being sampled if encountered in feeding and breeding areas (individual heterogeneity). Home feeding area represents the geographic preference of whales for one of six defined feeding areas. The initial population size for the model was 20,000, and whales were assigned to home feeding areas (Table 1) based on information from prior studies, preliminary results of a geographically stratified capture-recapture model (Calambokidis et al. 2008), and expert opinion within the SPLASH steering group.

The SimSPLASH model also includes parameters that are not specific to individuals. Mixing matrices defined the relative probabilities that an individual whale with a given home feeding area would be sampled in a given breeding area or a given feeding area (Table 2). The latter provides for mixing to occur among feeding areas; thus, the model does not constrain an individual to be sampled only in its home feeding area. The values used in the mixing matrices are not estimated from actual data but rather were chosen to simulate the type of movements seen in the North Pacific. The numbers of whales in each feeding and breeding area are not specified deterministically, but the expected numbers (Table 1) are a function of the home feeding area numbers and the mixing matrices. A non-calf survival rate specifies the likelihood that a non-calf would survive from one sampling occasion to the next (winter to summer or summer to winter). A calf survival rate specifies the survival of calves from winter to summer. Juvenile whales older than 6 mo were assigned the non-calf survival rate. New calves appear at the start of winter sampling, and

\footnotetext{
${ }^{3}$ The SimSPLASH program was written in $\mathrm{R}$ programming language and is available in online supplemental materials.
} 


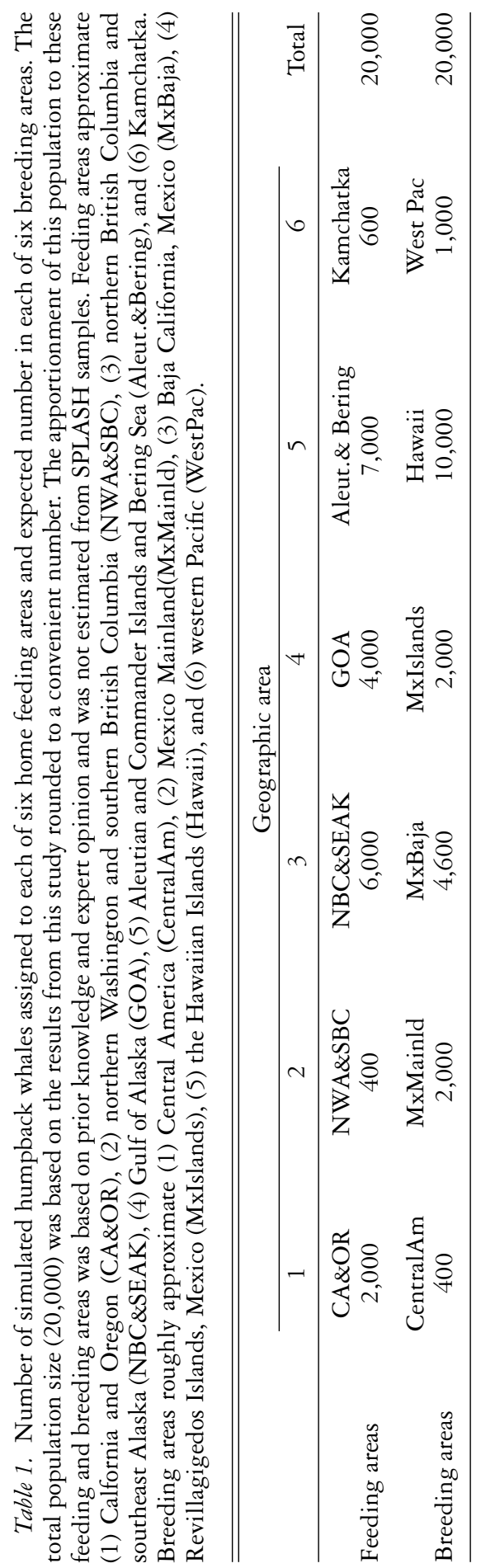


Table 2. Mixing matrices used in the simulation model to determine the relative probability that a whale assigned to a given home feeding area will be sampled in a specific breeding area or feeding area. Area names are given in Table 1.

\begin{tabular}{|c|c|c|c|c|c|c|c|}
\hline & \multirow[b]{2}{*}{$\begin{array}{l}\text { Home feeding } \\
\text { area }\end{array}$} & \multicolumn{6}{|c|}{ Breeding area } \\
\hline & & $\begin{array}{c}1 \\
\text { CentalAm }\end{array}$ & $\begin{array}{c}2 \\
\text { MxMainld }\end{array}$ & $\begin{array}{c}3 \\
\text { MxBaja }\end{array}$ & $\begin{array}{c}4 \\
\text { MxIslands }\end{array}$ & $\begin{array}{c}5 \\
\text { Hawaii }\end{array}$ & $\begin{array}{c}6 \\
\text { West Pac }\end{array}$ \\
\hline 1 & CA\&OR & 0.190 & 0.500 & 0.310 & 0.000 & 0.000 & 0.000 \\
\hline 2 & NWA\&SBC & 0.050 & 0.350 & 0.300 & 0.050 & 0.250 & 0.000 \\
\hline 3 & NBC\&SEAK & 0.000 & 0.050 & 0.080 & 0.100 & 0.750 & 0.020 \\
\hline 4 & GOA & 0.000 & 0.030 & 0.260 & 0.220 & 0.470 & 0.020 \\
\hline 5 & Aleut.\&Bering & 0.000 & 0.064 & 0.333 & 0.073 & 0.500 & 0.030 \\
\hline \multirow[t]{3}{*}{6} & Kamchatka & 0.000 & 0.000 & 0.000 & 0.000 & 0.050 & 0.950 \\
\hline & & \multicolumn{6}{|c|}{ Feeding area } \\
\hline & $\begin{array}{l}\text { Home feeding } \\
\text { area }\end{array}$ & $\begin{array}{c}1 \\
\text { CA\&OR }\end{array}$ & $\begin{array}{c}2 \\
\text { NWA\& } \\
\text { SBC }\end{array}$ & $\begin{array}{c}3 \\
\text { NBC\& } \\
\text { SEAK }\end{array}$ & $\begin{array}{c}4 \\
\text { GOA }\end{array}$ & $\begin{array}{c}5 \\
\text { Aleut.\& } \\
\text { Bering }\end{array}$ & $\begin{array}{c}6 \\
\text { Kamchatka }\end{array}$ \\
\hline 1 & CA\&OR & 0.990 & 0.010 & 0.000 & 0.000 & 0.000 & 0.000 \\
\hline 2 & NWA\&SBC & 0.050 & 0.850 & 0.100 & 0.000 & 0.000 & 0.000 \\
\hline 3 & NBC\&SEAK & 0.000 & 0.007 & 0.960 & 0.033 & 0.000 & 0.000 \\
\hline 4 & GOA & 0.000 & 0.000 & 0.050 & 0.918 & 0.032 & 0.000 \\
\hline 5 & Aleut.\&Bering & 0.000 & 0.000 & 0.000 & 0.020 & 0.970 & 0.010 \\
\hline 6 & Kamchatka & 0.000 & 0.000 & 0.000 & 0.000 & 0.120 & 0.880 \\
\hline
\end{tabular}

the number of new calves is stochastically determined as a fraction of the non-calf population. The model also includes a parameter for the relative probability of sampling a female in breeding areas (relative to a male) and parameters for the relative probabilities of sampling a calf in feeding and in breeding areas.

SimSPLASH simulates the photographic sampling of whales by stochastically selecting individuals from the "alive" population based on their multiplicative probability of being sampled using the rejection method. Sample sizes for each of the sampling areas and seasons were based on the sample sizes achieved in the actual SPLASH study (Table 3). An individual, $i$, is randomly selected from the "alive" population. The relative probability of it being sampled in area, $a$, and season, $s$, is estimated as

$$
\operatorname{Pr}\left(\operatorname{sampled}_{i, s, a}\right)=I_{i, s} \cdots S_{i, s} \cdots C_{i, s} \cdots H_{i, s, a}
$$

where $I=$ individual heterogeneity capture probability, $S=$ female sex bias in winter capture probability (relative to 1.0 for males), $C=$ capture probability for a calf (relative to 1.0 for non-calves), and $H=$ mixing probability for sample area $a$ given an individual's home area.

A uniform random number is generated for each randomly selected individual in the population, and that individual is classified as sampled if the random number is less than $\operatorname{Pr}$ (sampled). Unsampled individuals are returned to the population and can be randomly drawn again, but each individual can be sampled only once per season (mimicking our capture-recapture analysis). Within each season, the above sampling scheme is applied sequentially to each of the six sample areas until the 
Table 3. Sample sizes of distinct, photo-identified humpback whales during three seasons of sampling in each of six feeding areas and two seasons of sampling in each of six feeding areas (see Table 1 for area names). Counts are for high-quality identifications used in the capture-recapture analyses. Breeding season samples in the given calendar year include a few samples from December in the previous year.

\begin{tabular}{lccccccc}
\hline & \multicolumn{7}{c}{ Breeding area } \\
\cline { 2 - 8 } Season & $\begin{array}{c}1 \\
\text { CentalAm }\end{array}$ & $\begin{array}{c}2 \\
\text { MxMainld }\end{array}$ & $\begin{array}{c}3 \\
\text { MxBaja }\end{array}$ & $\begin{array}{c}4 \\
\text { MxIslands }\end{array}$ & $\begin{array}{c}5 \\
\text { Hawaii }\end{array}$ & $\begin{array}{c}6 \\
\text { WestPac }\end{array}$ & Total \\
\hline Breeding 2004 & 18 & 210 & 175 & 308 & 694 & 183 & 1,588 \\
Breeding 2005 & 45 & 252 & 149 & 192 & 838 & 209 & 1,685 \\
Breeding 2006 & 45 & 317 & 82 & 183 & 1,016 & 287 & 1,930 \\
& \multicolumn{7}{c}{ Feeding area } \\
\cline { 2 - 9 } & 1 & NWA\& & NBC\& & GOA & Aleut.\& & 6 & \\
Season & CA\&OR & SBC & SEAK & GOA & Bering & Kamchatka & Total \\
\hline Feeding 2004 & 248 & 72 & 1,167 & 923 & 289 & 25 & 2,724 \\
Feeding 2005 & 303 & 136 & 690 & 528 & 326 & 38 & 2,021 \\
\hline
\end{tabular}

actual SPLASH sample size is achieved for all areas. Between seasons, mortality rates are applied stochastically to each individual, and dead individuals are removed from future sampling. Births are added to the population between feeding and breeding area samples, and the number of births is determined stochastically from a binomial distribution based on the number of surviving non-calves and the birth rate.

Abundances from SimSPLASH were estimated for the same four adjacent pairs of sampling seasons as were estimated for the actual SPLASH samples, and an overall abundance was estimated from an average of the four values. An overall estimate was also calculated from a multiyear capture-recapture comparison between all feeding areas and all breeding areas, pooled over all seasons. To estimate bias, simulations were repeated for 100 stochastic realizations. Bias was calculated as the percentage difference between the estimated mean overall abundance from the 100 iterations and the realized mean abundance of "living" individuals in the model. Statistical uncertainty in the simulation results is represented as the $90 \% \mathrm{CI}$ in the resulting bias in estimating abundance (the 5th and 95th percentiles of the 100 simulations).

The SimSPLASH simulation was applied to 10 scenarios to test different potential sources of bias (Table 4). The base scenario 1 included no sources of potential bias and the home feeding area to winter area mixing matrix was identical for all feeding areas, and scenarios 2-10 added potential sources of bias to this base scenario. Scenario 2 included a three-times higher chance of sampling a male in breeding areas. Scenario 3 included births and deaths, with a non-calf survival rate of 0.96 per year $\left(0.98\right.$ between sampling periods) ${ }^{4}$ a calf survival rate of 0.85 between winter and feeding area samples (Gabriele et al. 2001), and a calf birth rate equal to $11 \%$ of the surviving non-calves before the winter sampling. Scenario 4 included geographically structured migration with different mixing probabilities for each

\footnotetext{
${ }^{4}$ Annual survival rates have been estimated to be 0.96 for humpback whales in the North Atlantic (Barlow and Clapham 1997) and in Hawaii and southeastern Alaska (Mizroch et al. 2004). Survival rate was estimated to be slightly higher (0.98) in Prince William Sound, Alaska (Mizroch et al. 2004).
} 


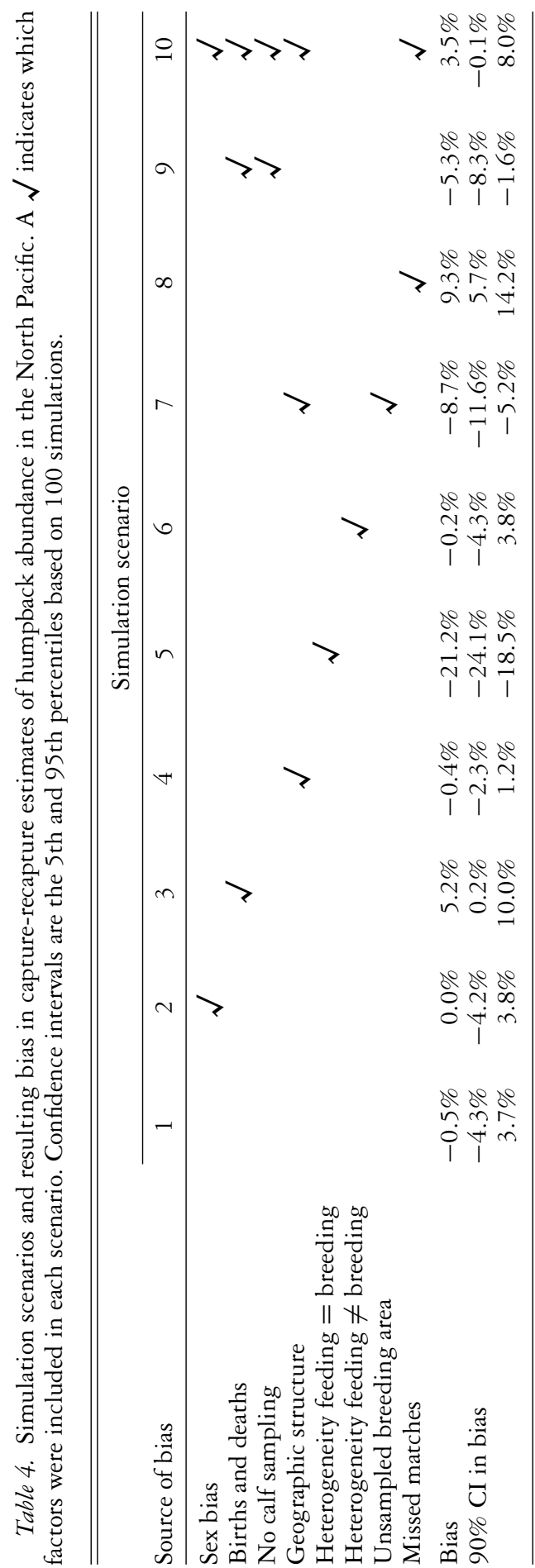




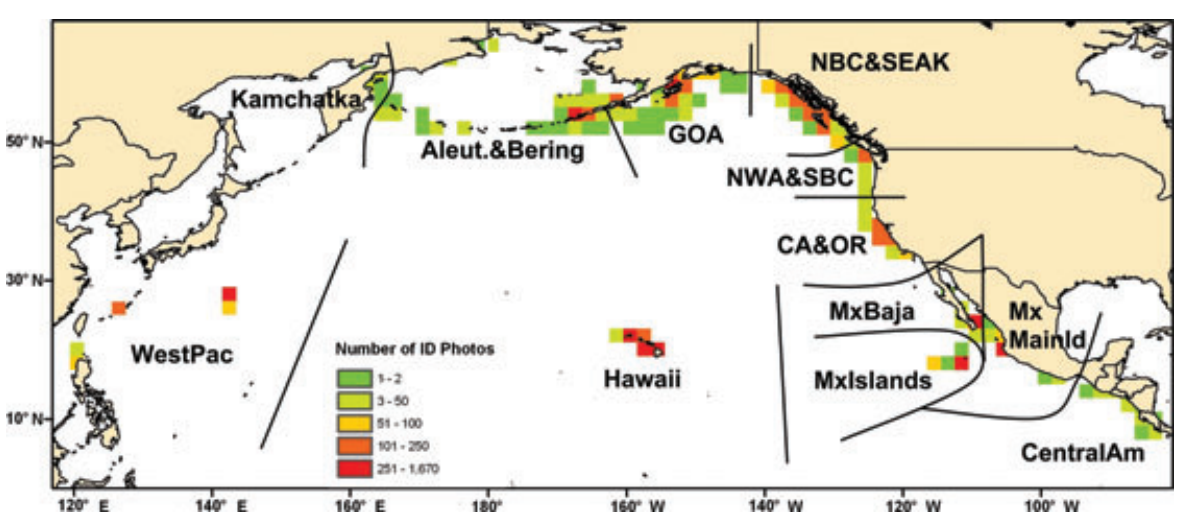

Figure 2. Geographic distribution of high-quality photo-identification samples taken for the SPLASH project tallied by $2 \times 2$ degree cells and geographic stratification for breeding and feeding areas (see abbreviations in Table 1).

of the feeding and breeding areas. Scenario 5 included individual heterogeneity in capture probabilities that are the same in the winter and summer; the heterogeneity value for each individual was drawn from a random uniform distribution between zero and one (simulating that individuals, when encountered, will vary in their relative probability of being sampled from zero to certainty). Scenario 6 included individual heterogeneity in capture probabilities that are different in the winter and summer; again, the heterogeneity values for each individual were drawn from a random uniform distribution between 0 and 1 . Scenario 7 included a seventh unsampled winter area as the migratory destination for $40 \%$ of the Aleutian/Bering home feeding area (see Migratory Destinations and Matching Rates below). Scenario 8 simulated missing $8.6 \%$ of existing matches when comparing adjacent sampling periods (see Error Rates below). Scenario 9 included births and deaths (same as scenario 3 ), but calves were not sampled in either breeding or feeding areas (when they are newborn and approximately 6 mo old, respectively). Finally, scenario 10 included the most likely factors causing bias in our SPLASH samples, combining scenarios 2, 4, 7,8 , and 9 . We did not include a scenario for incorrect matches because all matches were checked by a second person and incorrect matches are rarely if ever made for good quality photographs of humpback whale flukes (Stevick et al. 2001).

\section{RESULTS}

\section{Sampling Distribution}

The number of unique individuals that were photographically sampled each season varied from 1,588 to 1,930 for the three winters and from 2,724 to 2,021 for the two summers (Table 3). Photo-identification samples were poststratified into six breeding areas and six feeding areas (Fig. 2). Each of the six regions were sampled during each of our winter and summer sampling seasons, but sample sizes for each region varied among years due to logistical constraints. In general, however, the sample sizes for a given region varied by less than a factor of two among years (Table 3). A NOAA ship, the McArthur II, conducted 4 mo of dedicated SPLASH sampling in 2004, 
Table 5. Between-season matches of photo-identified humpback whales for each of six feeding areas and six breeding areas (see Table 1 for area names) for all seasons combined.

\begin{tabular}{|c|c|c|c|c|c|c|c|}
\hline & \multirow[b]{2}{*}{ Feeding area } & \multicolumn{6}{|c|}{ Breeding area } \\
\hline & & $\begin{array}{c}1 \\
\text { CentalAm }\end{array}$ & $\stackrel{2}{2}$ MxMainld & $\begin{array}{c}3 \\
\text { MxBaja }\end{array}$ & $\begin{array}{c}4 \\
\text { MxIslands }\end{array}$ & $\begin{array}{c}5 \\
\text { Hawaii }\end{array}$ & $\begin{array}{c}6 \\
\text { WestPac }\end{array}$ \\
\hline 1 & $\mathrm{CA \& OR}$ & 26 & 89 & 16 & & & \\
\hline 2 & NWA\&SBC & 3 & 18 & 7 & 2 & 18 & \\
\hline 3 & NBC\&SEAK & & 11 & 8 & 16 & 291 & \\
\hline 4 & GOA & & 25 & 22 & 50 & 150 & 2 \\
\hline 5 & Aleut.\& Bering & & 9 & 7 & 11 & 50 & 9 \\
\hline 6 & Kamchatka & & & & & & 21 \\
\hline
\end{tabular}

allowing us to collect a larger sample size in northern British Columbia, southeast Alaska, the Gulf of Alaska, and the Aleutian Islands in that year. That ship also allowed us to sample farther offshore in Alaska in 2004 than in 2005. Our sample sizes from Russia were smaller than expected in both years, and our sample sizes from western Pacific Islands were higher than expected in all 3 yr. Overall, we achieved broad geographic coverage in all sampling seasons and exceeded our expected sample sizes for most of our regions. Within each of the six geographic strata for winter and summer, sampling covered a wide area (Fig. 2).

\section{Migratory Destinations and Matching Rates}

The observed matches between feeding and breeding areas (Table 5, Fig. 3) largely confirmed patterns that have been observed in previous studies (reviewed by Calambokidis et al. 2001). Samples from the California/Oregon feeding area matched mostly to mainland Mexico and Central America. The northern Washington/southern British Columbia feeding area matched to a broad range of breeding areas from Central America to Hawaii. The vast majority of the northern British Columbia/southeast Alaska feeding area matched to Hawaii. A large fraction of the Gulf of Alaska and the Aleutian/Bering feeding areas also matched to Hawaii, but a surprising number also matched to Mexico's Islas Revillagigedos. This result indicates that many whales migrating between feeding areas in northern British Columbia and southeast Alaska and breeding areas in Hawaii cross paths with whales migrating between feeding areas in the Gulf of Alaska, Aleutian Islands, and Bering Sea and breeding areas near Mexico's offshore islands (as hypothesized by Norris et al. 1999 and Urbán et al. 2000 and confirmed by Witteveen et al. 2004). In previous studies, few matches had ever been found between the islands in the western Pacific (Japan and the Philippines) and any feeding area (Calambokidis et al. 2001). Our study is the first to show that the whales that winter in the western Pacific migrate primarily to Kamchatka and, to a lesser extent, the Aleutian Islands and Bering Sea.

The fraction of whales that match across seasons in different areas can provide insight into which areas were over- or undersampled relative to other areas. Among feeding areas (Fig. 4), Kamchatka had the highest overall match rate to breeding areas, and individuals sampled off Kamchatka matched only to the breeding areas of the western Pacific, so we infer that the western Pacific area was oversampled relative to other breeding areas. Feeding areas with large representation from the Hawaii 


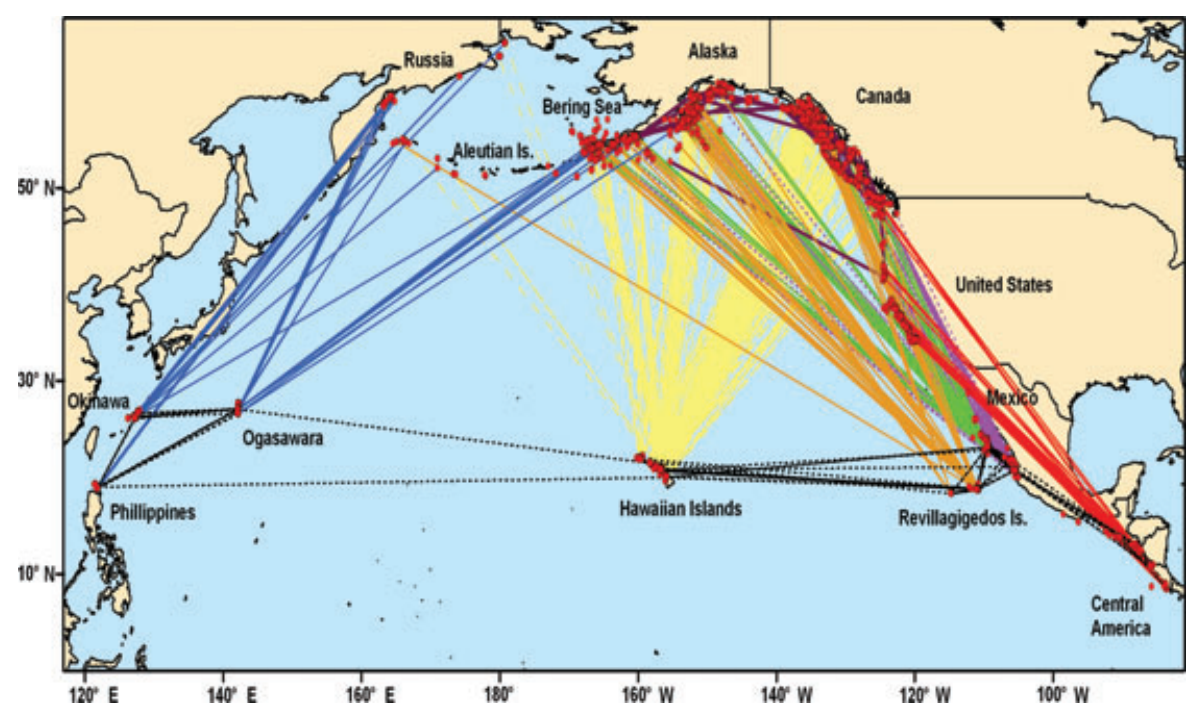

Figure 3. Locations of high-quality photo-identification samples (red dots) and photographic matches of distinct individuals (colored lines). Lines indicating matches are direct paths and are not intended to indicate migratory routes. Matches are not limited to temporally adjacent sampling season. Colors indicate matches between breeding and feeding areas (blue for western Pacific, yellow for Hawaii, tan for Mexican Islands, green for Baja California, Mexico, lavender for mainland Mexico, and red for Central America), among breeding areas (dotted black) and among feeding areas (purple).

breeding area had a lower percentage of overall matches to breeding areas, indicating that Hawaii was probably undersampled. The Aleutian Island/Bering Sea area had an especially low match rate to any breeding area. Other than Hawaii, the main destination for these whales (western Pacific) was likely oversampled, so there is no clear explanation for the low match rate for the Aleutian/Bering sample unless some whales from that location migrate to an unknown and unsampled breeding area.

For whales that were identified in breeding areas (Fig. 5), the lowest match rate to feeding areas was for the islands of the western Pacific. The feeding destinations for those whales (primarily Kamchatka and the Aleutian/Bering area) were almost certainly undersampled relative to other feeding areas. Breeding areas with a large representation from the California/Oregon feeding area (Central America and the Mexican mainland) had a higher matching rate than other breeding areas, indicating that the California/Oregon feeding area was likely oversampled relative to other feeding areas.

\section{Error Rates}

As with any photo-identification study, it was not possible to find all possible matches. When 266 known matches to previous seasons were added to the Winter 2006 photo collection prior to the matching process, 246 of these (92\%) were identified as matches. Match success rate ranged from a high of $96 \%$ for photographs with no quality scores at three (the poorest acceptable rating) to a low of $82 \%$ when 


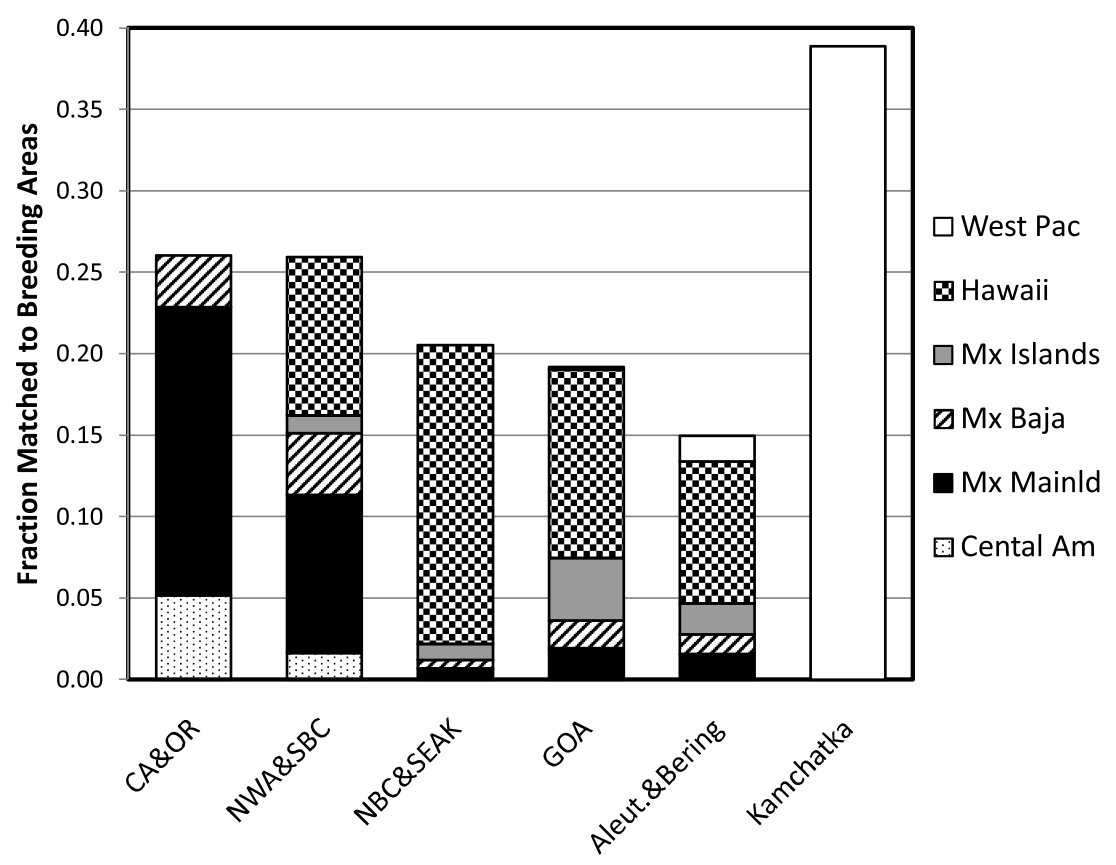

Figure 4. Fraction of high-quality photo-identifications from each of six feeding areas that match to samples from the indicated breeding areas.

three of the criteria were rated as a three (no more than three scores of three were allowed for the photograph to be included in the SPLASH comparison). The clarity of the photograph (i.e., quality score for focus) appeared to be the most important factor in whether a match was missed, with the largest difference in this category between the photographs where matches were found and those that were missed (mean score of 2.1 vs. 2.6, a highly significant difference, $t=2.84, P=0.007$ ). Similarly, when the quality scores of both the seeded match and the whale to which it matched were pooled, both the quality scores for exposure and focus were significantly better for whales for which the match was found relative to those that were missed $(t=2.20$ and 3.53, $P=0.04$ and 0.001 , for exposure and focus, respectively). In another test, when 165 fluke photographs that were known matches were compared to the catalog, 148 matches were found for a $90 \%$ success rate. In this test, matchers knew that a match was present and thus might have tried harder to find it. However, because the success rate in this second study was not statistically different from the blind study (Fisher exact test, $P=0.41$ ) we have combined both results and conclude that 91.4\% (394/431) of true matches would be found given our methods.

\section{Abundance Estimation}

Chapman-Petersen estimates of humpback abundance in the North Pacific (Table 6) are much greater for the mean of four adjacent feeding-to-breeding season estimates $(19,516)$ than for the mean within-winter estimate $(10,314)$ or the within-summer estimate $(10,109)$. This pattern has been seen in other studies of 


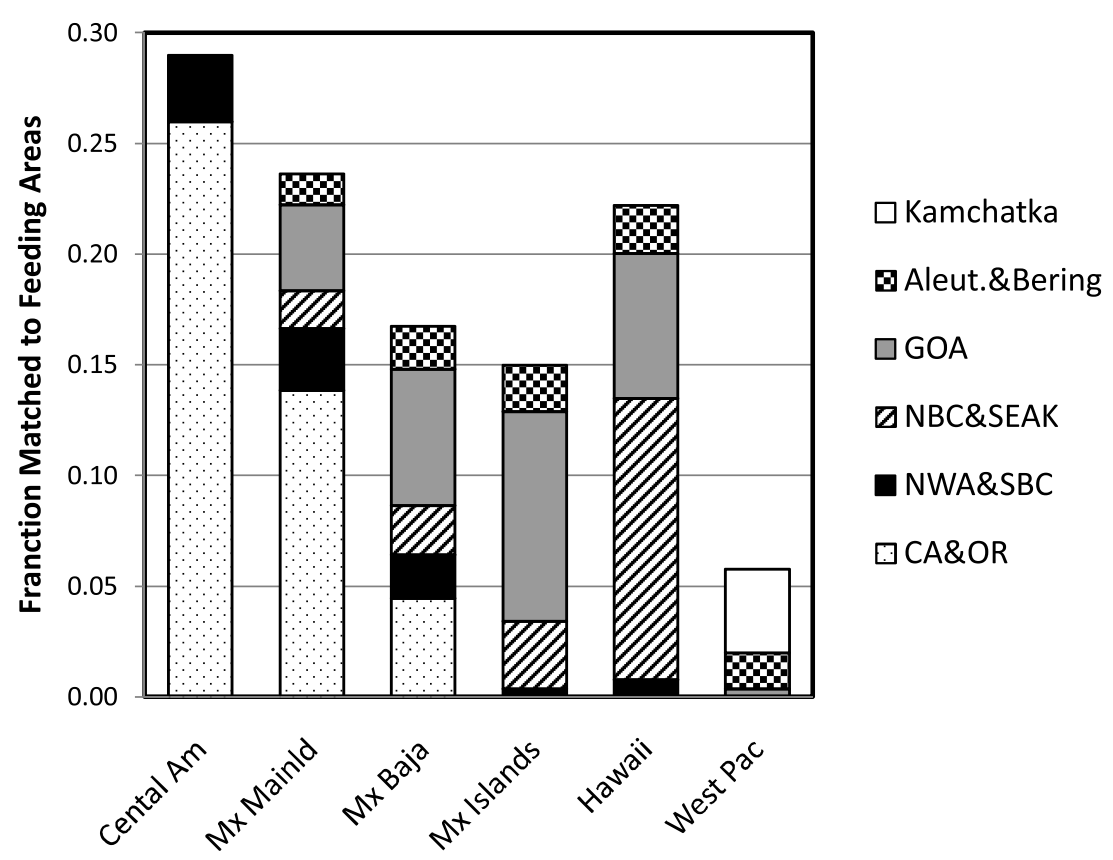

Figure 5. Fraction of high-quality photo-identifications from each of six breeding areas that match to samples from the indicated feeding areas.

humpback whale abundance (Smith et al. 1999). Within-season estimates tend to be negatively biased because sources of heterogeneity in sampling probability tend to be more similar between the capture and recapture occasions than for between-season estimates. Treating the four feeding-to-breeding estimates as independent estimates of population size (the number of matches should be independent), the empirical coefficient of variation $(\mathrm{CV}=0.04)$ shows that abundance is estimated very precisely. The capture-recapture estimate that combines all winter areas and all summer areas $(21,808)$ is larger than any of the individual between-season estimates. The analytical variance for this latter estimate also gives a very low coefficient of variation $(\mathrm{CV}=$ $0.027)$.

\section{Simulation Results}

Although empirical and analytical estimates of statistical uncertainty indicate that our estimates are precise, likely sources of bias contribute more to our overall uncertainty than does sampling variation (Table 4). The largest single source of bias in the SimSPLASH simulation study $(-21.2 \%)$ occurred when there was a high level of individual heterogeneity and this individual heterogeneity was constant in both breeding and feeding areas (scenario 5). The same average levels of individual heterogeneity but with different randomly chosen values in winter and summer (scenario 6) resulted in a mean bias of $-0.2 \%$, and the $90 \% \mathrm{CI}$ of this estimate includes zero bias. The second largest source of bias (+9.3\%) occurred when $8.6 \%$ of true matches were not found. This bias can be accurately approximated if the 


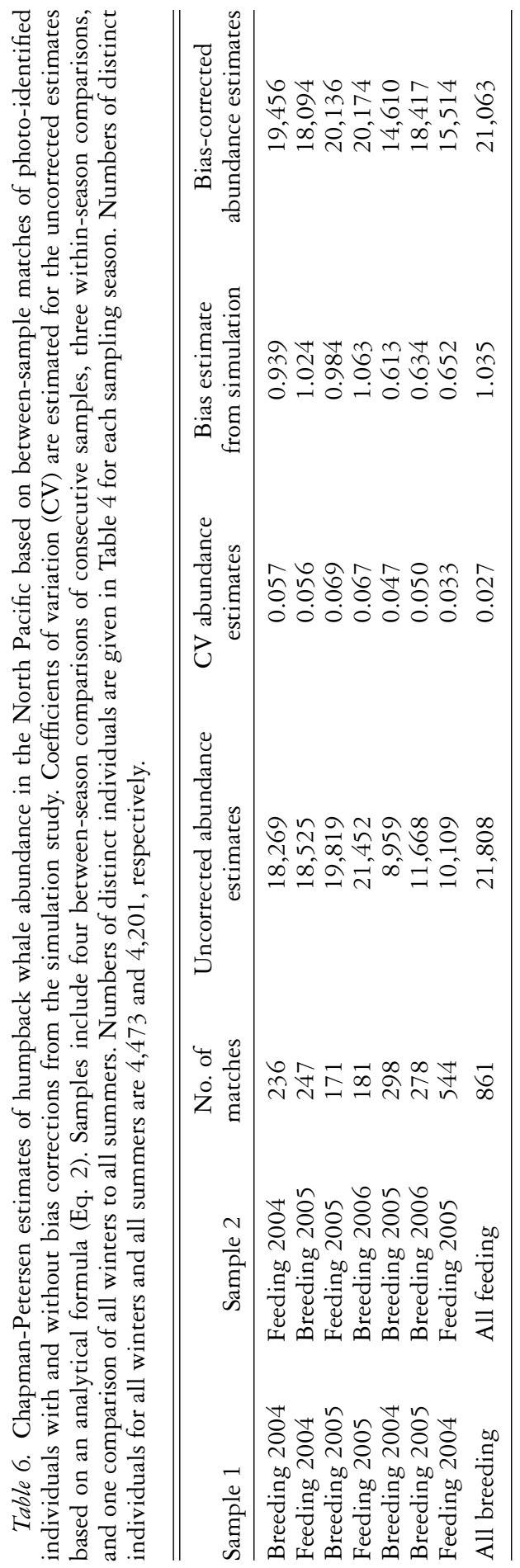


probability of missed matches is known; in this case the probability of finding a match was 0.914 and, because the number of matches appears in the denominator of the capture-recapture estimator, the bias can be approximated as 1/0.914 or 9.4\% (see Stevick et al. 2001 for a better approximation for correcting estimates for missed matches). The third largest source of bias $(-8.7 \%)$ occurred when the simulation sampling was geographically structured and when $40 \%$ of the whales in the Aleutian/Bering feeding area migrated to an unsampled breeding area (scenario 7). The fourth largest source of bias $(-5.3 \%)$ occurred in simulation scenario 9 , which included births and deaths (which by itself added $\mathrm{a}+5.2 \%$ bias) and which excluded calves from photographic sampling (which added a much larger negative bias). In this case, population growth by itself added a positive bias because of a violation in the assumption of population closure (Hammond 1986) and the exclusion of calves added a negative bias because a large segment of the population $(11 \%$ in this simulation) was simply excluded from the estimate. The overall bias in simulation scenario $9(-5.3 \%)$ can be approximated as the bias from births and death $(+5.2 \%)$ minus the percentage of calves in the population $(11 \%)$. A realistic simulation of geographically structured sampling (scenario 4) added, by itself, only a small bias $-0.4 \%$ ). Sex-biased sampling (three males per female) in winter (scenario 2) did not add any appreciable bias in abundance estimates.

\section{Bias-Corrected Abundance Estimates}

Many appreciable biases were identified in the simulation study that could lead to either over- or underestimation of population size. Our sampling certainly included some of those sources of bias: births and deaths certainly did occur, calves were not sampled because they seldom show their flukes, not all individuals had the same probability of being sampled if encountered, and only approximately $91.4 \%$ of matches were found. Scenario 10 included all of these known sources of bias and resulted in a net bias of only $+3.5 \%$ in the comparison between all feeding area and all breeding area samples. We use this estimate of bias to correct our capturerecapture population estimates (Table 6). While individual heterogeneity in capture probability certainly exists for both feeding and breeding areas, we have not estimated a measure of heterogeneity and therefore did not include a correction for that negative bias. We do not believe that the same patterns of individual heterogeneity are likely to occur on feeding and breeding areas (scenario 5) because behaviors are so different in those areas. Insufficient information exists to calculate the covariation between individual heterogeneity in feeding and breeding areas. An unsampled breeding area is suspected to exist, which we hypothesize is the migratory destination for a significant fraction of individuals from the Aleutian/Bering area, which would also lead to a negative bias in our estimates. However, until this area is found and sampled, we do not feel confident enough to include simulation scenario 7 in our bias correction. Overall, the residual biases in our estimate are likely to result in an underestimate of true humpback whale abundance.

\section{Discussion}

\section{Abundance Estimation}

The best estimate of 2004-2006 humpback whale abundance in the North Pacific is the bias-corrected estimate from the comparison of all breeding areas and all 
feeding areas pooled over all years $(n=21,063)$. Stevick et al. (2003) also concluded that this method of pooling multiple sampling periods within breeding and feeding areas produced the best estimate of North Atlantic humpback whale abundance from the YONAH samples. Our pooled estimate is based on a larger sample size (approximately one-fifth of the population sampled in both breeding and feeding areas) than the comparisons between adjacent seasons (Table 6). A large sample size helps ensure more representative sampling and lower bias because, as the sample approaches the population size, bias asymptotically approaches zero. This reduction in sampling heterogeneity (which causes a negative bias) with sample size may help explain why the pooled estimate based on all winters and all summers is higher than any of the estimates based on just adjacent seasons. Our best estimate of statistical precision is our empirical coefficient of variation $(\mathrm{CV}=0.04)$ for the mean of estimates for four between-season comparisons. This estimate includes aspects of sampling variation and population growth that are not included in the analytical estimate of precision for the pooled estimate $(\mathrm{CV}=0.027)$. This estimate of precision does not estimate all sources of uncertainty in our population estimate (see below).

Our estimate of the abundance of humpback whales in the North Pacific $(\sim 21,000$ after accounting for most known biases) is larger than any recent estimates and exceeds some earlier estimates of pre-whaling abundance. Other suspected biases are likely to be negative, so the true population is likely to be even greater than reported here. Our estimate is considerably higher than the only other recent estimate of abundance for the entire North Pacific ( 6,000-10,000) based on the photo-identification capturerecapture study using data from 1990 to 1993 (Calambokidis et al. 1997). Using the median estimate of 8,000 from that study, this increase by a factor of 2.75 over approximately $13 \mathrm{yr}$ corresponds to a population growth rate of $8.1 \%$ per year. No other estimates exist for the growth rate of the North Pacific population as a whole, but Calambokidis et al. (1999) estimated a growth rate of approximately $8 \%$ per year for the population along the U.S. West Coast from 1988-1989 to 1997-1998, Mizroch et al. (2004) estimates a population growth rate of $10 \%$ for Hawaii in 1979-1996, and Zerbini et al. (2006) estimated a population growth rate of 6.6\% $(95 \% \mathrm{CI}=5.2 \%-8.6 \%)$ for the population around the Alaska Peninsula and eastern Aleutian Islands in 2001-2003. All these estimates of population growth appear to be internally consistent, but different populations may be growing at different rates.

\section{Biases and Heterogeneity}

The simulations presented here clearly show that biases inherent in our twosample capture-recapture model contribute more to the uncertainty in our estimates of humpback whale abundance than does sampling variance. Biases due to individual heterogeneity in capture probabilities are especially large if the same heterogeneity occurs on both sampling occasions. In our simulations, we considered individuals to have relative capture probabilities from zero to one, with a uniform distribution between these two values. In the extreme case for which this probability does not change between capture occasions, the bias leads to a $21 \%$ underestimate of the true population size. A bias of this magnitude is not likely to occur in our estimates because we deliberately chose capture occasions to be in different seasonal habitats when behaviors are very different. Using the same range of heterogeneity in capture probability but with different values in different seasons resulted in a very small bias. 
Sex bias in sampling is one common cause of heterogeneity in capture probability, but again our simulation studies show that this effect is small if one of the two capture occasions is unbiased with respect to sex. It is worth noting that, for most abundance estimation studies based on line-transect sampling, a coefficient of variation (CV) of $21 \%$ is considered good. The extreme case of a $21 \%$ bias seems like a very large uncertainty given the $\mathrm{CV}$ in our abundance estimate but would be well within the range of sampling variation in many other studies of whale abundance. More work is needed to quantify individual heterogeneity in capture probabilities so that this bias can be estimated.

The problem of missed matches leads to a more easily corrected source of bias. It is virtually impossible to find every matching fluke in a sample of over 18,000 photographs. Our estimate of missed matches $(8.6 \%)$ is higher than the overall error rate of $3.4 \%$ found by Stevick et al. (2001) based on a comparison of photographic and genetic matches from the YONAH project. This difference might be due to the short cuts we took in order to conduct this study with a much larger sample size than the YONAH study. The most important thing is to measure the error rate so that this source of bias can be corrected. Our simulation-based bias correction cannot be easily applied to other studies, but we recommend that the Stevick-ChapmanPetersen formula (Stevick et al. 2001) be used to estimate abundance whenever the fraction of missed matches can be measured.

Failure to meet the assumption of a closed population can lead to other significant biases. In our study of the entire North Pacific population, we can be certain that immigration and emigration are not sources of bias. The population is, however, dynamic, with births adding new individuals and deaths removing others; both of these processes will lead to an overestimation of population size. If birth and death rates can be estimated, the magnitude of this bias can be estimated from simulations (as in this study) or from an analytical approach. In our study, we deliberately excluded calves from our samples because they are much less likely to show their flukes than are other age classes. In this way, we avoided a bias that we could not easily estimate (heterogeneity in likelihood of calves and non-calves to be sampled) for a bias that could more easily be estimated (from the fraction of calves in the population).

Bias correction is clearly an important component to any capture-recapture project to estimate whale abundance. Some biases remain difficult to estimate (such as those due to behavioral heterogeneity or unknown/unsampled areas), but some can easily be corrected if the study is designed to collect ancillary information. Among the most important information for bias correction is the probability of missing a match, the fraction of calves in the population, and the mortality rates of calves and noncalves. The parallel identification of photo-identified individuals using microsatellite genotyping of biopsy samples could be used to improve estimates of error rates for photographic matching (Stevick et al. 2001, Garrigue et al. 2004).

\section{ACKNOWLEDGMENTS}

Photographic sampling for the SPLASH project was accomplished by over 400 dedicated humpback whale researchers representing more than 50 research groups throughout the North Pacific; a full list of photographic contributors is included in Appendix A of the supplemental online material. Funding and other support were provided by the NOAA Fisheries Service, NOAA National Marine Sanctuary Program, National Fish and Wildlife Foundation, Pacific Life Foundation, Fisheries and Oceans Canada, and the Commission for Environmental Cooperation. Initial matching and data processing for regional collections were primarily 
done by Jennifer Cedarleaf, Holly Fearnbach, Ursula Gonzalez, Alan Ligon, and Cornelia Oedekoven. Matching of the SPLASH photographs received from regional coordinators took place at Cascadia Research by Andrea Bendlin, Dominique Camacho, Kiirsten Flynn, Andrea Havron, Jessica Huggins, and Nora Maloney. This report was improved by the comments and suggestions of Gretchen Steiger and Aly Fleming. Field work in Mexico was done under permits of the Secretaria del Medio Ambiente y Recursos Naturales (SEMARNAT). Map graphics were produced by Jim Carretta.

\section{Literature Cited}

Baker, C. S., and L. M. Herman. 1987. Alternative population estimates of humpback whales (Megaptera novaeangliae) in Hawaiian waters. Canadian Journal Zoology 65:28182821.

Baker, C. S., L. Herman, A. Perry, W. Lawton, J. Straley, A. Wolman, H. Winn, J. Hall, G. Kaufman, J. Reinke and J. Ostman. 1986. The migratory movement and population structure of humpback whales (Megaptera novaeangliae) in the central and eastern North Pacific. Marine Ecology Progress Series 31:105-119.

Baker, C. S., J. M. Straley and A. Perry. 1992. Population characteristics of individually identified humpback whales in southeastern Alaska: Summer and fall 1986. Fishery Bulletin 90:429-437.

Baker, C. S., L. Medrano-Gonzalez, J. Calambokidis, A. Perry, F. Pichler, H. Rosenbaum, J. M. Straley, J. Urban-Ramirez, M. Yamaguchi and O. von Ziegesar. 1998. Population structure of nuclear and mitochondrial DNA variation among humpback whales in the North Pacific. Molecular Ecology 6:695-707.

Barlow, J., and P. J. Clapham. 1997. A new birth interval approach to estimating demographic parameters of humpback whales. Ecology 78:535-546.

Barlow, J., and K. A. Forney. 2007. Abundance and population density of cetaceans in the California Current ecosystem. Fishery Bulletin 105:509-526.

Buckland, S. T., D. R. Anderson, K. P. Burnham, J. L. Laake, D. L. Borchers and L. Thomas. 2001. Introduction to Distance Sampling: Estimating abundance of biological populations. Oxford University Press, Oxford, UK.

Burnham, K. P., and D. R. Anderson. 1976. Mathematical models for nonparametric inferences from line transect data. Biometrics 32:325-336.

Calambokidis, J., and J. Barlow. 2004. Abundance of blue and humpback whales in the eastern North Pacific estimated by capture-recapture and line-transect methods. Marine Mammal Science 21:63-85.

Calambokidis, J., G. H. Steiger, J. M. Straley, T. Quinn, L. M. Herman, S. Cerchio, D. R. Salden, M. Yamaguchi, F. Sato, J. R. Urban, J. Jacobsen, O. VonZeigesar, K. C. Balcomb, C. M. Gabriele, M. E. Dahlheim, N. Higashi, S. Uchida, J. K. B. Ford, Y. Miyamura, P. Ladron de Guevara, S. A. Mizroch, L. Schlender and K. Rasmussen. 1997. Abundance and population structure of humpback whales in the North Pacific basin. Final Contract Report 50ABNF500113 to Southwest Fisheries Science Center, P. O. Box 271, La Jolla, CA $92038.72 \mathrm{pp}$.

Calambokidis, J., T. Chandler, K. Rasmussen, G. H. Steiger and L. Schlender. 1999. Humpback and blue whale photo-identification research off California, Oregon and Washington in 1998. Contract Report to Southwest Fisheries Science Center, P. O. Box 271, La Jolla, CA 92038.35 pp.

Calambokidis, J., G. H. Steiger, J. M. Straley, L. M. Herman, S. Cerchio, D. R. Salden, J. Urbán-R, J. K. Jacobsen, O. von Ziegesar, K. C. Balcomb, C. M. Gabriele, M. E. Dahlheim, S. Uchida, G. Ellis, Y. Miyamura, P. Ladrón de Guevara-P., M. Yamaguchi, F. Sata, S. A. Mizroch, L. Schlender, K. Rasmussen, J. Barlow and T. J. Quinn II. 2001. Movements and population structure of humpback whales in the North Pacific. Marine Mammal Science 17:769-974. 
Calambokidis, J., E. A. Falcone, T. J. Quinn, A. M. Burdin, P. J. Clapham, J. K. B. Ford, C. M. Gabriele, R. LeDuc, D. Mattila, L. Rojas-Bracho, J. M. Straley, B. L. Taylor, J. Urbán-R, D. Weller, B. H. Witteveen, K. Wynne, M. Yamaguchi, A. Bendlin, D. Camacho, K. Flynn, A. Havron, J. Huggins and N. Maloney. 2008. SPLASH: Structure of populations, levels of abundance and status of humpback whales in the North Pacific. Final report for Contract AB133F-03-RP-00078. 57 pp.

Carothers, A. D. 1979. Quantifying unequal catchability and its effect on survival estimates in actual an population. Journal of Animal Ecology 48:863-869.

Cerchio, S. 1998. Estimates of humpback whale abundance off Kauai, 1989 to 1993: Evaluating biases associated with sampling the Hawaiian Islands breeding assemblage. Marine Ecology Progress Series 175:23-34.

Chapman, D. G. 1951. Some properties of the hypergeometric distribution with applications to zoological censuses. University of California Publications in Statistics 1:131-160.

Darling, J. D., K. M. Gibson and G. K. Silber. 1983. Observations on the abundance and behavior of humpback whales (Megaptera novaeangliae) off West Maui, Hawaii, 1977-79. Pages 201-222 in R. S. Payne, ed. Communication and behavior of whales. Westview Press, Bolder, CO.

Friday, N. A., T. D. Smith, P. T. Stevick, J. Allen and T. Fernald. 2008. Balancing bias and precision in capture-recapture estimates of abundance. Marine Mammal Science 24:253-275.

Gabriele, Christine M., J. M. Straley, S. A. Mizroch, C. S. Baker, A. S. Craig, L. M. Herman, D. Glockner-Ferrari, M. Ferrari, S. Cerchio, O. von Ziegesar, J. Darling, D. McSweeney, T. J. Quinn III and J. K. Jacobsen. 2001. Estimating the mortality rate of humpback whale calves in the central North Pacific Ocean. Canadian Journal Zoology 79:589-600.

Gambell, R. 1976. World whale stocks. Mammal Review 6:41-53.

Garrigue, C., R. Dodemont, D. Steele and C. S. Baker. 2004. Organismal and 'gametic' capture-recapture using microsatellite genotyping confirm low abundance and reproductive autonomy of humpback whales on the wintering grounds of New Caledonia. Marine Ecology Progress Series 274:251-262.

Hammond, P. S. 1986. Estimating the size of naturally marked whale populations using capture-recapture techniques. Report of the International Whaling Commission (Special Issue 8):253-282.

Hammond, P. S. 1990. Heterogeneity in the Gulf of Maine? Estimating humpback whale population size when capture probabilities are not equal. Report of the International Whaling Commission (Special Issue 12):135-140.

Hilborn, R. 1990. Determination of fish movement patterns from tag recoveries using maximum likelihood estimators. Canadian Journal of Fisheries and Aquatic Sciences 47:635643.

Hwang, W. D., and A. Chao. 1995. Quantifying the effects of unequal catchabilities on Jolly-Seber estimators via sample coverage. Biometrics 51:128-141.

Johnson, J. H., and A. A. Wolman. 1984. The humpback whale, Megaptera novaeangliae. Marine Fisheries Review 46:30-37.

Katona, S., B. Baxter, O. Brazier, S. Kraus, J. Perkins and H. Whitehead, H. 1979. Identification of humpback whales by fluke photographs. Pages 33-44 in H. E. Winn and B. L. Olla, eds. Behavior of marine animals: Current perspectives in research. 3. Cetaceans. Plenum Press, New York, NY.

Kendall, W. L., K. H. Pollock and C. Brownie. 1995. A likelihood-based approach to capturerecapture estimation of demographic parameters under the robust design. Biometrics 51:293-308.

Mackintosh, N. A. 1946. The natural history of whalebone whales. Biological Reviews 21:60_ 74.

Mizroch, S. A., L. M. Herman, J. M. Straley, D. A. Glockner-Ferrari, C. Jurasz, J. Darling, S. Cerchio, C. M. Gabriele, D. R. Salden and O. von Ziegesar. 2004. Estimating the adult survival rate of central North Pacific humpback whales (Megaptera novaeangliae). Journal of Mammalogy 85:963-972. 
Mobley, J. R., Jr., S. Spitz and R. Grotefendt. 2001. Abundance of humpback whales in Hawaiian waters: Results of 1993-2000 aerial surveys. Report for the Hawaiian Islands Humpback Whale National Marine Sanctuary. 16 pp.

Norris, T. F., M. McDonald and J. Barlow. 1999. Acoustic detections of singing humpback whales (Megaptera novaeangliae) in the eastern North Pacific during their northbound migration. Journal Acoustic Society America 106:506-514.

Palsbøll, P. J., J. Allen, M. Bérubé, P. J. Clapham, T. P. Feddersen, P. S. Hammond, R. R. Hudson, H. Jørgensen, S. Katona, A. Holm Larsen, F. Larsen, J. Lien, D. K. Mattila, J. Sigurjónsson, R. Sears, T. Smith, R. Sponer, P. Stevick and N. Øien. 1997. Genetic tagging of humpback whales. Nature 388:767-769.

Petersen, C. G. J. 1896. The yearly immigration of young plaice into the Limfjord from the German Sea. Report of the Danish Biological Station for 1895, 6:1-77.

Pledger, S., and M. Efford. 1998. Correction of bias due to heterogeneous capture probability in capture-recapture studies of open populations. Biometrics 54:888-898.

Rice, D. W. 1978. The humpback whale in the North Pacific: Distribution, exploitation, and numbers. Pages 29-44 in K. S. Norris and R. R. Reeves, eds. Report on a workshop on problems related to humpback whales (Megaptera novaeangliae) in Hawaii. Contract Report to the U.S. Marine Mammal Commission. NTIS PB-280-794. 90 pp.

Seber, G. A. F. 1982. The estimation of animal abundance and related parameters. Macmillan Press, New York, NY.

Smith, T. D., J. Allen, P. J. Clapham, P. S. Hammond, S. Katona, F. Larsen, J. Lien, D. Mattila, P. J. Palsbøll, J. Sigurjónsson, P. T. Stevick and N. Øien. 1999. An ocean-basin-wide mark-recapture study of the North Atlantic humpback whale (Megaptera novaeangliae). Marine Mammal Science 15:1-32.

Stevick, P. T., P. J. Palsbøll, T. D. Smith, M. V. Bravington and P. S. Hammond. 2001. Errors in identification using natural markings: Rates, sources, and effects on capture recapture estimates of abundance. Canadian Journal of Fisheries and Aquatic Sciences 58:1861-1870.

Stevick, P. T., J. Allen, P. J. Clapham, N. Friday, S. K. Katona, F. Larsen, J. Lien, D. K. Mattila, P. J. Palsbøll, J. Sigurjónsson, T. D. Smith, N. Øien and P. S. Hammond. 2003. North Atlantic humpback whale abundance and rate of increase four decades after protection from whaling. Marine Ecology Progress Series 258:263-273.

Straley, J. M., T. J. Quinn III and C. M. Gabriele. 2009. Assessment of mark-recapture models to estimate the abundance of a humpback whale feeding aggregation in Southeast Alaska. Journal of Biogeography 36:427-438.

Urbán R., J., C. Alverez F., M. Salinas Z., J. Jacobson, K. C. Balcomb III, A. Jaramillo L., P. L. de Guevara P. and A. Aguayo L. 1999. Population size of humpback whale, Megaptera novaeangliae, in waters off the Pacific coast of Mexico. Fishery Bulletin 97:1017-1024.

Urbán R., J., A. Jaramillo L., A. Aguayo L., P. Ladrón de Guevara P., M. Salinas Z., C. Alvarez F., L. Medrano G., J. Jacobson, K. C. Balcomb III, D. E. Claridge, J. Calambokidis, G. H. Steiger, J. M. Straley, O. von Ziegesar, J. M. Waite, S. Mizroch, D. E. Dahlheim, J. D. Darling and C. S. Baker. 2000. Migratory destinations of humpback whales wintering in the Mexican Pacific. Journal of Cetacean Research and Management 2:101-110.

Witteveen, B. H., J. M. Straley, O. von Ziegesar, D. Steel and C. S. Baker. 2004. Abundance and mtDNA differentiation of humpback whales (Megaptera novaeangliae) in the Shumagin Islands, Alaska. Canadian Journal of Zoology 82: 1352-1359.

Zerbini, A. N., J. M. Waite, J. L. Laake and P. R. Wade. 2006. Abundance, trends and distribution of baleen whales off Western Alaska and the central Aleutian Islands. Deep Sea Research Part I: Oceanographic Research Papers 53:1772-1790.

Received: 8 October 2009

Accepted: 8 September 2010 